\title{
The 1998 Russian crisis: could the exchange rate volatility have predicted it?
}

\author{
Olivier Basdevant ${ }^{\mathrm{a}}$, Stephen G. Hall ${ }^{\mathrm{b}}$ \\ ${ }^{a}$ Department of Economics, University of Pretoria, Pretoria, South Africa \\ ${ }^{b}$ Imperial College Management School, London, UK
}

\begin{abstract}
The purpose of this paper is to examine the exchange rate volatility of the ruble, before the August 1998 crisis, using a macro-economic model of the Russian Federation developed by Basdevant (2000). A main focus of this paper is to use this simulation exercise to find out what was the origin of this financial crisis. This paper will show how expectations of the exchange rate played a crucial role. Nevertheless, this analysis does not seek to only explain the Russian crisis by a specific shock on expectations the objective is also to provide an analysis of the timing of the crisis. A further objective is to demonstrate a new methodology that allows an econometric model to be used to forecast the possibility of financial crises.
\end{abstract}

Finally this paper demonstrates that a model can be used to assess the likelihood of an unusual event such as the Russian financial crisis by exploiting the information, which is contained in the model's own residual process. Using this technique we demonstrate that the variance of exchange rates produced by the model rose dramatically in anticipation of the full height of crises in 1988.

Keywords: Macro-modelling; Structural change; Russia; Stochastic simulations

\section{Introduction}

The purpose of this paper is to examine the exchange rate volatility of the ruble, before the August 1998 crisis, using a macro-economic model of the Russian Federation developed by Basdevant (2000).

The main issue is to use this simulation exercise to find out what was the origin of this financial crisis. This paper will show how expectations of the exchange rate played a crucial role. Nevertheless this analysis does not seek to only explain the Russian crisis by a specific shock on expectations. The objective is also to provide an analysis of the timing of the crisis rather than the crisis itself. A further objective is to demonstrate a new methodology, which allows an econometric model to be used to forecast the possibility of financial crises. The origin of the Russian crisis lay in structural problems: mainly capital stock obsolescence and shortage (see Basdevant, 2000 or Hall \& Basdevant, 1999) as well as institutional ones. In particular the two main aspects are: the co-operation (or lack of) between industry and the banking system, and the inefficiency of markets (there is no real 
market clearing, and non-cash transactions are widespread).

Before presenting the model and simulation results, it is necessary to characterise the crisis with some stylised facts, as the model should obviously reflect these.

The crisis began on August 17, 1998, when Prime Minister Kirienko announced that the government would allow the ruble to be devaluated $34 \%$ by the end of the year. He also declared a 90-day foreign debt moratorium, and announced a de-facto default on the government's domestic bond obligations. On August 26th the Russian Central Bank announced that it would not be able to support the ruble any longer. In less than a month the national currency collapsed by $300 \%$, from 6.2 rubles to the dollar to over 20. Inflation shot up 15\% in August compared with $0.2 \%$ in July, and has continued to climb.

As stressed by Krugman (1979) financial crises occur when countries tend to finance government expenditures by printing money, which can lead to a currency crisis, as the fixed exchange rate regime becomes unsustainable. It is quite remarkable that in Russia the financial crisis came after the currency crisis. This lead to a total collapse of the banking system. Kaminsky and Reinhart (1999) link currency crises to banking system crises for a number of industrial and developing countries. They emphasise that the peak of a banking crisis most often comes after a currency crisis. Moreover they insist on the fact that most often banking crises have preceded currency crises. In the case of Russia, the crisis came mainly from the inability of the government to raise enough taxes to reduce the public deficit. Hence it became indebted towards international creditors, and thus rendered the Russian Federation dependent on capital inflows. The ruble was kept at a fixed exchange rate because of a fall in reserves. According to most Russians official the question before the 1998 crisis was not whether a crisis was going to happen - as the ruble was obviously over evaluated - but simply when the crisis was going to happen. 
Therefore this model will be used to evaluate the timing of the crisis, emphasising that the crisis came from the continuation of a policy of a fixed exchange rate (even with a relative flexibility between a certain band) that was unsustainable. Therefore we implicitly consider that - contrarily to what usually happens in financial crisis - the collapse of the banking system was not the cause of the crash. This approach can be related to other studies as Mishkin (1996) or Stoker (1994) who consider the same causal relation as the one defended in this paper.

To analyse the timing of the crisis we propose a new methodology which draws on ideas from the financial econometric literature on ARCH and GARCH modelling and the standard macro-economic literature on stochastic simulations to derive a time varying measure of the probability of a financial crises occurring. Further details are given below but essentially the idea is that the model and its errors are a complete description of the data generation process. Any mis-specification or omitted effect from the model is, by definition captured in the errors of each equation. So unless the crisis happens without any warning either the model, or its error processes should be able to predict that something is going to occur. We therefore propose using the technique of stochastic simulation to calculate the standard error bands of the model variables. But instead of doing this in the conventional way where the shocks are drawn from a constant distribution we will base the distribution of the shocks on the properties of the very recent model residuals, much as is done in a standard ARCH model. We will thus be able to calculate a time varying volatility profile for each variable in the model. If the technique is successful we would expect the volatility (or standard error) of variables such as the exchange rate to increase dramatically just prior to the crises. Thus indicating the rising probability of such a crisis.

The rest of the paper is organised as the following: Section 2 describes the modelling of the exchange rate, Section 3 presents stochastic simulations results, and Section 4 concludes. In Section 5 a summarised structure of the model is presented. The completed model is presented and discussed in Basdevant (2000).

\section{Modelling the exchange rate}

The notion that domestic interest rates are in some way related to foreign interest rates is standard in financial economics. Basic arbitrage relationships such as the covered interest rate parity condition (CIP) state that the return on foreign assets covered by a forward exchange contract should equal the return on a domestic asset of the same risk type. If markets are characterised by perfect mobility of capital, the following equation holds:

$$
1+i_{t}=\left(1+i_{t}^{*}\right) \frac{\mathrm{EE}_{t+1}}{E_{t}}
$$


where $E_{t}$ is the spot exchange rate and $\mathrm{EE}_{t+1}$ the forward exchange rate in $t$ for delivery in $t+1$. This equation can be rewritten, approximating the log of $1+i_{t}$

by $i_{t}$ :

$$
e_{t}=\mathrm{ee}_{t+1}+i_{t}^{*}-i_{t}
$$

where $e$ and ee are the logs of $E$ and EE, respectively and a rise in $e$ signifies an increase in the price of foreign currency, or a depreciation in the domestic currency. A number of studies decompose the forward exchange rate in two components: the expected future exchange rate and the risk premium $\pi$. Normally the following equation stands:

$$
e_{t}=\hat{e}_{t}+i_{t}^{*}-i_{t}+\pi_{t}
$$

where $\pi_{t}$ is the risk premium and $\hat{e}_{t}$ the expectation build in $t$ on the exchange rate in $t+1$. In the absence of a risk premium, or if agents are risk neutral, this equation is known as uncovered interest parity (UIP).

An understanding of the evolution of the exchange rate requires an understanding of how agents form their expectations. Therefore, the model of the exchange rate first determines how agents form their expectations, and then incorporates it in the exchange rate function. Rational expectations as an approach to the expectations formation process has come under attack because it assumes too much information on the part of agents. As an alternative, a learning process in building expectations may be considered. It may therefore be assumed that agents' expectations are on average correct, but that only a limited set of information is utilised. Hence a relatively simple representation of expectations is possible, avoiding systematic errors in a model similar to the one by Feige and Pearce (1976), in which agents are assumed to use only a univariate model to form their expectations. While implementing a learning process, it should be emphasised that that agents will adjust the expectations rule when they observe the errors they make, and the weights they assign to the different variables used to form their expectations will be adjusted accordingly. More precisely, following Hall (1987, 1993b) and Hall and Garratt (1995, 1997), the use of a Kalman filter allows for the estimation of how agents adjust their expectations, i.e., for the estimation of time varying parameters that simulate the learning process.

\subsection{Expectations on the exchange rate}

As mentioned previously, the expected exchange rate does not follow rational expectations: rather agents use the observed exchange rate and the evolution of oil prices and consumer prices to build their expectations. The expectation rule we adopt has the following form:

$$
\Delta \log \left(\mathrm{EE}_{t}\right)=\Delta \log \left(\mathrm{CPI}_{t-1}\right)-0.02 \mathrm{NIR}_{t-1}+\varepsilon_{t}^{\mathrm{EE}}
$$

where NIR is net international reserves. 
It is quite crucial to point that the change in expectations depends on a time varying constant, $\varepsilon^{\mathrm{EE}}$. This coefficient can be interpreted economically in this case as a measure of the share of expectations that are related not to real anchors (like inflation or change in reserves) but rather to more psychological insight of what is likely to happen. In other words, expectations depend not only on fundamentals but also on a game between all agents interfering on financial markets, where each participant has to anticipate the behaviour of others. The fact that the timing of financial crisis can hardly been anticipated (which applies particularly well to the Russian crisis) comes mostly from the fact that anticipations are not rational and are therefore not based on fundamentals but also on psychology of agents. They may globally decide to go on a financial bubble, even if it is a common knowledge that it is unsustainable. This is obvious in the simulation made (see Section 3.3) were the volatility of expectations on the exchange rate precedes the increase in the volatility of other variables. We can therefore explain in a rather simple way why it was so difficult to forecast the timing of the crisis: it is mainly because it depends on how people form their expectations, and the way they form it is complicated enough to render difficult any prediction on the timing. Nevertheless this should also be viewed as a suggestion for future investigation on theoretical and empirical studies on learning process in expectations formation.

\subsection{The exchange rate}

The exchange rate was specified in Eq. (3) as a function of exchange rate expectations, the interest differential and a risk premium. Exchange rate expectations were specified in Eq. (4), as a function of past exchange rates, the inflation differential, real growth differential and the current account. The fundamentals of the exchange rate are therefore established; it is also possible to explain how the exchange rate will adjust to disturbances in the fundamentals.

From the equation defining exchange rate expectations, the effect of the current account emerges as a major anchor of the exchange rate. The exchange rate function (cf Eq. (3)) allows for a link with the domestic economy through the domestic interest rate. More precisely, the equation is estimated as follows:

$$
\log \left(E_{t}\right)=\log \left(\mathrm{EE}_{t}\right)-\left(\frac{\mathrm{DR}_{t}-\mathrm{FR}_{t}}{400}\right)+\pi_{t}^{E}
$$

where $E$ is the nominal exchange rate, ${ }^{1 \mathrm{EE}_{t}}$ the expectation made in $t$ for $E_{t+1}$, DR the domestic interest rate and FR the foreign interest rate, ${ }^{2} \pi_{t}$ is the risk premium, estimated with the state equation:

$$
\pi_{t}=\pi_{t-1}+\eta_{t}
$$

\footnotetext{
${ }^{1}$ Taken from the Central Bank of Russia.

${ }^{2}$ Taken from OECD.
} 


\section{Stochastic simulations}

\subsection{Methodology adopted}

In this section we outline the new way of applying stochastic simulations which we are proposing in this paper. Stochastic simulations (a variant of the Monte-Carlo method applied to econometric models) is a technique for calculating the standard error of a models forecast or simulation properties which has been used for many years (a survey of the technique may be found in Hall \& Henry, 1988).

In general notation the reduced form of a non-linear model may be described as follows,

$$
\boldsymbol{Y}_{t}=f\left(\boldsymbol{B}(\boldsymbol{L}) \boldsymbol{X}_{t}, \boldsymbol{e}_{t}, \boldsymbol{\alpha}\right)
$$

where $\boldsymbol{Y}$ is a vector of endogenous variables, $\boldsymbol{B}(\boldsymbol{L})$ is a lag polynomial matrix, $\boldsymbol{X}$ is the vector of exogenous variables, $e$ is the vector of structural errors and $\alpha$ is the vector of model parameters. If we assume that $e_{t} \sim N(0, \boldsymbol{\Omega})$ then stochastic simulations allow us to calculate numerically the variance of $\boldsymbol{Y}_{t}$. The conventional practice is to assume that the covariance matrix $\Omega$ is constant over time and it is typically measured by a range of existing techniques surveyed in Hall and Henry (1988). In this application, however, we want to capture the information, which may be in the errors about the changing probability of a crisis. We therefore assume that $\Omega$ follows a standard ARCH process. That is:

$$
\boldsymbol{\Omega} \sim \mathrm{NID}\left(0, \sum_{i=1}^{k} \tau_{i} \boldsymbol{e}_{t-i}^{2}\right)
$$

When we then run the stochastic simulation based on this variance matrix we generate the time varying variances of all the endogenous variables implied by this ARCH process. We need to specify both the lag length, $k$, and the weighting parameters, $\tau_{i}$, to fully specify the model. Clearly we want to specify $k$ as quite a small number as we want to capture the most recent information contained in the models errors. We decided that as the model is quarterly and structural change seems to be very rapid in Russia, a maximum lag of four was desirable. In addition given this fairly short lag length we decided to use an equal weighting system.

\subsection{Validation of the model using variance analysis}

From Fig. 1 it can be seen that the model is able to reproduce a higher volatility of the exchange rate as the simulation period gets closer to the crisis. It is also worth noticing that in the scale of the 7-axis is the standard deviation deflated by the simulated value of the exchange rate, namely $\sigma(e) / e$. This was convenient to purge the results from a scaling effect: as the simulation date get closer to the crisis the exchange rate is rising, which can be sufficient to induce a higher variance. 


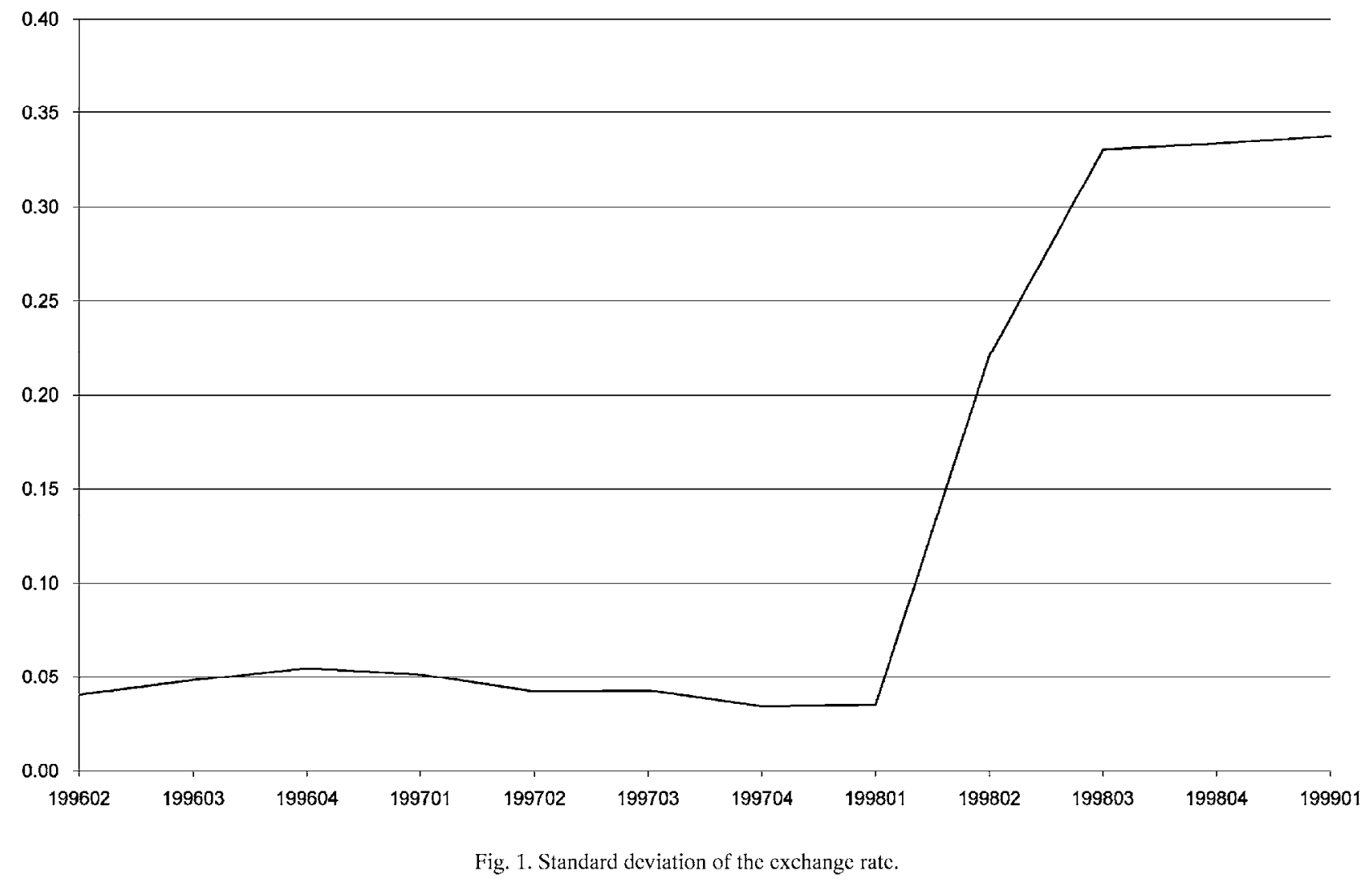


The crisis happened in the third quarter of 1998. With the proposed simulations the variance reaches a maximum exactly at this date, and begins to grow just the quarter before.

\subsection{Explaining the crisis}

Using this simulation, it is also possible to find out what shocks were the main cause of this higher volatility. In the following diagram all the variables with a sharp change in variance are included.

As can be seen in Fig. 2 the main changes occur in the exchange rate and expected exchange rate equations (see solid lines). The interesting property is that expected exchange rate variance is rising at the same time that the exchange rate. From Eqs. (14) and (15) it can be seen that the current level of expectations affects the level of the exchange rate. In other words, the greater variance of the exchange rate comes from a greater variance of expectations, as shocks on the latter will currently affect the former. Hence the turning point is explained by a higher volatility of expectations that has induced a higher volatility in the exchange rate.

Following this increase, imports reacts also after two quarters, while exports variance remains stable: exports are less sensitive to a change in exchange rate. As Russian exports are mainly products for which prices are fixed on international markets (e.g., oil) thus they do not respond to a depreciation (or appreciation) of the ruble.

One of the results of devaluation is inflation, as many intermediate goods as well as consumption goods are imported. Moreover many prices are set in dollars, as a result of the large dollarisation of the economy. Thus, when the ruble fluctuates there is a snowball effect on domestic inflation.

\subsection{Policy implications}

The policy implications of this model has been discussed in Basdevant (2000). Nevertheless this contribution, insisting on the role of expectations in the crisis, completes an analysis that has stressed the key role of public investments. In the rest of this section we recall the main results obtained by the model in terms of policy recommendations, and explain the implications of simulations proposed in this article.

There were two key elements for the Russian crisis to occur:

- The lack of competitiveness of the economy, especially at market prices, given the capital stock obsolescence, which explains the crisis itself.

- The change in expectations, which explains the crisis timing.

From the point of view of policy makers those two elements are actually just the reflect of one thing: a policy dominated by corruption, inappropriate measures (e.g., the exchange rate was obviously over evaluated) and inability to define and 


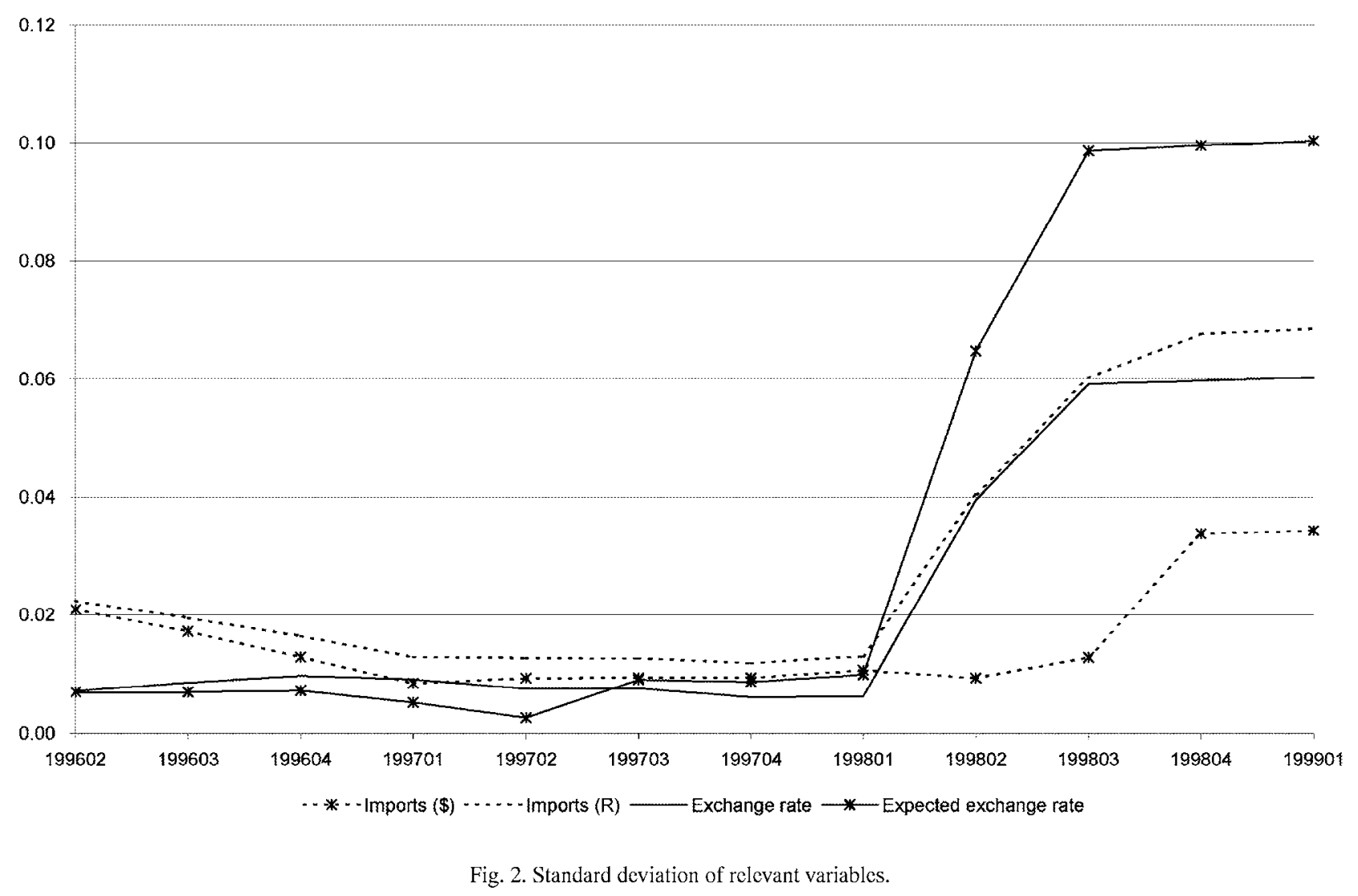


implement a consistent policy (e.g., the frequent changes of prime ministers under the last 2 years of Eltsine's presidency) will be sanctioned by markets. The basis of a sustainable policy should actually not only consist in good governance, e.g., by targeting a specific budget deficit to GDP ratio. The policy should mostly focus on strengthening long-run growth. This is actually a crucial problem for many countries, as Governments' horizons are mostly bounded by forthcoming elections rather than long-run objectives. It is obviously a great source of danger for countries like the Russian Federation because their current problems have mostly just long-term answers.

It is also possible to understand the severity of the crisis using this model. Actually the mean reason has just had been exposed: the major problem is the capital stock obsolescence. But the severity of the crisis was also largely due to the collapse of the financial bubble on GKOs. This came from a change in expectations, and in the crisis aftermath investors totally turned their expectations and the rubble had to face constant speculative attacks that worsened the economic situation. It emphasises again how expectations may have major roles in crisis, even if those crisis have much more profound reasons to happen.

Nevertheless the economic situation improved rather rapidly after the crisis. This was partly due to the sharp increase in oil prices that fortunately happened in the crisis aftermath, but also because the devaluation allowed using additional productive capacities that were again valuable at market prices (see Anderson et al., 2000). Hence devaluation induced a standard imports substitution effect, improving the trade balance on non-energy products. ${ }^{3}$ All problems where not solved by the devaluation, mostly because the debt to GDP ratio substantially increased after the crisis. Basically the Russian economy still needs to rebuild its capital stock (see Basdevant, 2000; Hall \& Basdevant, 1999). Therefore the representation of the economy in this model emphasises that a more pro-active economic policy should help in fostering investment and improve the economic situation, in the short- as well as the medium-term. More precisely a measure aimed at rebuilding the capital stock might have positive effects: after public authorities intervention the private sector is able to go on and invest itself, contributing to further growth, as the economy should be less constrained by the capital stock obsolescence. Moreover it is worth noticing that in this specific model public investment should actually help private investment rather than crowd it out. This mostly comes from the supply-side constraint on the economy that prevents private investors to implement profitable projects, simply because resources required are not available.

If public investment may increase productivity, it is important to recall that it depends a lot on how public intervention is able to define and implement productive investment, practical issues of corruption or purely political and strategic considerations are then raised. Of course this is not as important as it would be if the recommendation was to promote the capital stock only with public

\footnotetext{
${ }^{3}$ As an example exports of non-energy products at constant prices increased by $15 \%$ during the year 1999.
} 
investments, which is not the case, as the role of public intervention is just to undertake the first step, i.e., to first increase capital stock.

\section{Conclusion}

In this paper we have demonstrated that a model can be used to assess the likelihood of an unusual event such as the Russian financial crisis by exploiting the information which is contained in the models own residual process. Using this technique we have demonstrated that the variance of exchange rates produced by the model rose dramatically in anticipation of the full crises in 1988. This paper has also shown how expectations formation is crucial in understanding the timing the magnitude of the crisis.

Following the crisis the progress made were rather impressive with a strong output recovery and the achievement of a financial stability. A favourable external environment has contributed to the recent success, and Russian producers have benefited from the devaluation to reuse a part of the capital stock. However, many of the structural problems that were present before the 1998 crisis still remain to be tackled. Hence, recent achievements, particularly on growth, are vulnerable to a major deterioration in the environment. The main challenge facing the authorities remains the need to implement a broad-based acceleration of structural reform, to ensure that the recovery and the stabilisation gains will be sustained over the medium term.

It is a major challenge for the Putin's administration to define and conduct a policy addressing long-run issues faced by the Russian economy. This would form the basis to prevent another financial crisis, but should also provide the stability and credibility that is needed to attract private investors who should provide ultimately the only solution to Russian economic issues. This not only means to attract foreign investors and to benefit from technology transfers (see Bayoumi, Coe, \& Helpman, 1996; Coe, Helpman, \& Hoffmaister, 1995; Temple, 1999), but also simply to attract Russian investors and to stop capital flight.

\section{Annex}

The complete model is presented here, with more details given in Basdevant (2000). It is also available on the web site (http://www.col.ru/eeg/model/present. html). Basically this model is drawn on the ideas of Hall (1993a) or Greenslade and Hall (1996) that despite structural change econometric modelling can still be useful if it takes explicitly into account the form of change, which has taken place. Therefore the model incorporates those two main features:

- In the long-run the Russian economy should conform to economic theory. Hence, many long-run parameters can be calibrated according to theory. 
Structural change makes some coefficient unstable, and also has lead to a measurement problem.

\subsection{Methodology}

The basic structure is a variant of an equilibrium correction model (ECM) that sets the following form for each endogenous variable $\boldsymbol{X}_{t}$ :

$$
\Delta \boldsymbol{X}_{t}=\sum_{i=1}^{K}\left(\alpha_{0 i} \Delta \boldsymbol{X}_{t-i}+\alpha_{1 i} \Delta_{t-i}\right)-\gamma\left(\boldsymbol{X}_{t-1}-\boldsymbol{X}_{t-1}^{*}-\varepsilon\right)+\boldsymbol{v}_{t}
$$

where $\boldsymbol{X}_{t}$ is a vector that represents other variables that influence the dynamics of $\boldsymbol{X}_{t}$, and $\boldsymbol{X}_{t}^{*}+\varepsilon$ is the long-run value for $\boldsymbol{X}_{t}$, where e is a constant, $\boldsymbol{X}_{t}^{*}$ is a linear combination of different variables and $v_{t}$ a white noise. The second-term of the equation is the equilibrium correction term: when $\boldsymbol{X}_{t}$ is above its long-run target, then it tends to render the variation of $\boldsymbol{X}_{t}$ negative, and then makes $\boldsymbol{X}_{t}$ move back to the target. The first-term describes the short-run dynamic followed by $\boldsymbol{X}_{t}$.

The lag depth was limited to two in order to preserve degrees of freedom.

To deal with the structural change the results of Clements and Hendry (1996a, 1996b, 1998a) Hendry and Clements (1998b) are implemented who demonstrate that changes in the deterministic component of a model dominate its forecasting

performance. The main implication of this work is that consistent intercept adjustment may compensate for a wide range of structural change. This was implemented by introducing a time varying constant (estimated with a Kalman filter) in each ECM equation. Hence the basic ECM has been changed in order to specify the rule for $\varepsilon$ :

$$
\begin{aligned}
& \Delta \boldsymbol{X}_{t}=\sum_{i=1}^{k}\left(\alpha_{0 i} \Delta \boldsymbol{X}_{t-i}+\alpha_{1 i} \Delta_{t-i}\right)-\gamma\left(\boldsymbol{X}_{t-1}-\boldsymbol{X}_{t-1}^{*}-\varepsilon_{t}\right)+\boldsymbol{v}_{t} \\
& \varepsilon_{t}=\varepsilon_{t-1}+\delta_{t}
\end{aligned}
$$

where $v_{t}$ and $\delta_{t}$ are white noises. Using a Kalman filter on this structure allows the computation of data for $\varepsilon_{t}$ that adjusted to the structural change (see Hall, 1993a) for greater details on the use of Kalman filter. All the other coefficients where calibrated.

\subsection{Modelling the supply-side}

As the official measures of the capital stock in Russia show no decline in the capital stock over the transition period, it has been chosen to compute an effective capital stock which will then explain the fall in potential output. This is discussed more fully in Hall and Basdevant (1999).

Briefly, the technology is assumed to be a Cobb-Douglas. Output is a measured variable, which is assumed to be generated by the following measurement 
equation:

$$
\log \left(Y_{t}\right)=\alpha_{0}+\alpha_{1} \log \left(K_{t}\right)+\alpha_{2} \log \left(N_{t}\right)+\varepsilon_{t}
$$

where $Y$ and $N$ are directly observed variables while $K$ is an unobserved state variable. The effective capital stock is generated by the following state equation:

$$
\log \left(K_{t}\right)=\log \left(K_{t-1}\right)+\log \left(\frac{1+\mathrm{TI}_{t}}{K_{0}}\right)-\delta_{t-1}+v_{1 t}
$$

This is a standard state equation in the $\log \left(K_{t}\right), 1+\mathrm{TI} / K$ is total investment expressed in proportional terms. Total investment is the sum of private investment $I$, foreign direct investment (FDI) and public investment GI:

$$
\mathrm{TI}_{t}=I_{t}+\mathrm{GI}_{t}+\mathrm{FDI}_{t}
$$

$\delta_{t-1}$ is the unobserved rate of depreciation of the capital stock and $v_{1 t}$ is an error term. The unobserved depreciation rate is then assumed to be generated by a second state equation where $v_{2 t}$ is also an error term:

$$
\delta_{t}=\delta_{t-1}+v_{2 t}
$$

So the depreciation rate follows a random walk which allows it to freely increase to allow for the higher rate of scrapping during the transformation period in Russia. Together these three equations form a simple state space model and the Kalman filter may be used to estimate the unobserved effective capital stock and the rate of depreciation.

This system defines total supply in the model and hence a supply-side constraint: in the real sector as many long-run relations depend on the output gap (the difference between potential and real output). Hence, the expansion of the economy depends on the ability of the economy to expand domestic production that is to say on the capacity for the capital stock to expand output. ${ }^{4}$

\subsection{The lack of a market clearing condition and the output gap}

The assumption of market clearing obviously does not hold in Russia. Hence the reduced form equations should reflect both supply and demand factors. This is another way to take into account the structural change, as a basic result is that the economy does not evolves along an equilibrium path. More precisely in some GDP components (consumption, investment and exports) were introduced the output gap.

Let's consider now a brief description of those equations. For each variable $X$ the variable $\varepsilon^{X}$ refers to the time varying parameter that is estimated with a Kalman filter.

\footnotetext{
${ }^{4}$ This is also the reason why an appropriate policy should first focus on rebuilding the capital stock.
} 
The evolution of consumption is given by:

$$
\begin{gathered}
\Delta \log \left(C_{t}\right)=0.2 \Delta \log \left(Y_{t}-\mathrm{TT}_{t}+\mathrm{GTR}_{t}\right)+0.2 \log \left(\frac{\mathrm{YPF}_{t-1}}{Y_{t}}\right) \\
-0.3\left(\log \left(\frac{C_{t-1}}{Y_{t-1}-\mathrm{TT}_{t-1}+\mathrm{GTR}_{t-1}}\right)\right. \\
\left.+0.2 \log \left(\mathrm{WAR}_{t-1}\right)+\varepsilon_{t}^{C}\right)
\end{gathered}
$$

where $C$ is consumption, TT total taxes, GTR net transfers, $Y$ - TT net disposable income, YPF the potential output defined with the production function, $\log (\mathrm{YPF} / 7)$ the output gap, and finally WAR is wage arrears. The long-run relation has been calibrated with a strong Keynesian structure where consumption depends on current income. Also, as Ivanova and Wyplosz (1999) state, the increase of wage arrears are a spontaneous response to a key failure of the Russian economy: firms use their worker and providers as implicit bankers because they have no access to proper credit. Then, wage arrears may be seen as forced saving. The evolution of investment is given by:

$$
\begin{aligned}
\Delta \log \left(I_{t}\right)= & 0.4 \Delta \log \left(I_{t-1}\right)+0.4 \log \left(\frac{\mathrm{YPF}_{t-1}}{Y_{t-1}}\right) \\
& -0.5 \log \left(\frac{I_{t-1}}{Y_{t-1}-\mathrm{TT}_{t-1}+\mathrm{GTR}_{t-1}}\right)+\varepsilon_{t}^{I}
\end{aligned}
$$

where $I$ is investment. At present no detectable influence of interest rates on investment is observable (it may be that interest rate is not an adequate proxy for the cost of capital, see Gavrilenkov, Henry, \& Nixon, 1999).

FDI is sensitive to external shocks and financial crisis, which increase the risk factor of new investments. In Russia FDI represents only $0.8 \%$ of GDP (source: United Nations, EBRD). It is then worth noticing that a way to improve the transition process is to promote FDI in Russia. ${ }^{5}$ We adopt a simple specification, where FDI depends on the volatility in the exchange rate: foreign investors are willing to invest in Russia only when the current situation is stable:

$$
\begin{aligned}
\Delta \mathrm{FDI}_{t}=0.4 \Delta \mathrm{FDI}_{t-1}-0.2\left(\mathrm{FDI}_{t-1}-0.05 \mathrm{TREND}\right. & \\
& \left.+0.302\left(\frac{E_{t}-E_{t-1}}{E_{t-1}}\right)^{2}\right)+\varepsilon_{t}^{\mathrm{FDI}}
\end{aligned}
$$

where TREND is a linear trend.

\footnotetext{
${ }^{5}$ Moreover so far much of FDI were in Moscow (around $50 \%$ of FDI in Russia were located in Moscow in 1995, and for 1996-1967 this share went up to 70\%, source: Goskomstat), and FDI in Russia are low compared with other emerging markets. For example, between 1994 and 1998 cumulative FDI in Russia was estimated at about US\$9 billion, which is below cumulative FDI inflows in Poland (US\$12 billion) or Hungary (US\$17 billion).
} 
The equation for exports is almost standard, and depend on exchange rate $(E)$, world price index (WPPI) on the output gap and oil prices. As for consumption and investment, a durable increase of exports will be possible only if there is an improvement of potential output. It is also worth noticing the positive effect of oil prices on exports, Russia's external sources of income mainly come from oil and gas.

$$
\begin{aligned}
\Delta \log \left(\mathrm{XS}_{t}\right)= & 0.2 \log \left(\mathrm{XS}_{t-1}\right)+0.2 \Delta \log \left(\frac{\mathrm{OP}_{t-1}}{\mathrm{WPPI}_{t-1}}\right) \\
& +0.3 \log \left(\frac{\mathrm{YPF}_{t-1}}{Y_{t-1}}\right)-0.5\left(\log \left(\mathrm{XS}_{t-1}\right)-\log \left(\mathrm{WY}_{t-1}\right)\right. \\
& \left.-0.05 \log \left(\mathrm{ER}_{t-1}\right)-0.1 \log \left(\frac{\mathrm{OP}_{t-1}}{\mathrm{WPPI}_{t-1}}\right)\right)
\end{aligned}
$$

Employment follows output in the long-run:

$$
\Delta \log N_{t}=0.2 \Delta \log N_{t-1}+0.1 \Delta \log Y_{t-1}+0.4 \log \left(\frac{\mathrm{YPF}_{t-1}}{Y_{t-1}}\right)+\varepsilon_{t}^{N}
$$

where $N$ is employment, it will evolve according to the marginal labour cost that is a proportion of potential output (as the production function is CobbDouglas). Due to this property, a durable increase in employment requires first an increase in potential output, which again emphasis the major role of investment and the capital stock.

\subsection{Prices}

Another interesting property of the Russian economy is the large use of the dollar in many transactions. As many prices are set in dollars any change in the exchange rate has an immediate effect on prices. For that reason the consumer price index, CPI, depends on the current variation in the exchange rate:

$$
\begin{aligned}
\Delta \log \left(\mathrm{CPI}_{t}\right)= & 0.2 \Delta \log E_{t}+0.2 \Delta \log \left(\mathrm{CPI}_{t-1}\right)+0.4 \Delta \log \left(\mathrm{PPI}_{t-1}\right) \\
& +0.05 \Delta \log \left(M 2_{t-1}\right)+0.05 \Delta \log \left(M 2_{t-2}\right) \\
& -0.58\left(\log \mathrm{CPI}_{t-1}-0.5 \log \mathrm{PPI}_{t-1}-0.5 \log E_{t-1}\right)+\varepsilon_{t}^{\mathrm{CPI}}
\end{aligned}
$$

where PPI is the producer price index, $M 2$ the money supply ${ }^{6}$ and $E$ is the nominal exchange rate. In the long-run the CPI is constrained to follow the evolution of the PPI and the exchange rate.

The PPI depends on both wages and the exchange rate, in order to reflect the influence of costs on prices. It is also important to notice that in a highly dollarized

\footnotetext{
${ }^{6}$ Taken from the Central Bank of Russia.
} 
economy like the Russian one, the exchange rate has a signal effect. Firms use the exchange rate as a signal to increase their own prices, even if they are not explicitly quoted in dollars (see Grafe, Kirsanova, \& Wyplosz, 1996). Moreover the PPI depends also on the output gap: an increase in demand relatively to potential output will induce higher prices.

$$
\begin{aligned}
\Delta \log \left(\mathrm{PPI}_{t}\right)= & 0.1 \Delta \log \left(E_{t-1}\right)+0.3 \Delta \log \left(\mathrm{WN}_{t-1}\right)+0.5 \Delta \log \left(\mathrm{PPI}_{t-1}\right) \\
& -0.1 \log \left(\frac{\mathrm{YPF}_{t-1}}{Y_{t-1}}\right)-0.4\left(\log \mathrm{PPI}_{t-1}-0.6 \log \mathrm{WN}_{t-1}\right. \\
& \left.-0.4 \log E_{t-1}\right)+\varepsilon_{t}^{\mathrm{PPI}}
\end{aligned}
$$

where $\mathrm{WN}$ is nominal wages.

\subsection{The economic policy}

Government expenditures are divided between investment (GI) and consumption (GC), debt burden (GINT) and transfers (GTR). The interest in the distinction between GI and GC lies in the fact that investment directly contributes to the stock of capital. Moreover, due to the specification of the private investment function, this will also have a positive influence on private investment, as it does not depends on interest rate. Hence, total government expenditures GT is given by:

$$
\mathrm{GT}_{t}=\mathrm{GC}_{t}+\mathrm{GI}_{t}+\mathrm{GTR}_{t}+\mathrm{GINT}_{t}
$$

Government revenues are composed by taxes (TT) and non-tax revenue (NTR). The model has a complex treatment of taxes but conceptually it may be thought of as allowing taxes to grow in line with output after allowing for various special effects:

$$
\begin{aligned}
& \Delta \log \left(\mathrm{TT}_{t}\right)=\Delta \log \left(Y_{t}\right) \\
& \Delta \log \left(\mathrm{NTR}_{t}\right)=\Delta \log \left(Y_{t}\right)
\end{aligned}
$$

Then, the total revenue (REV) is the sum of TT and NTR:

$$
\mathrm{REV}_{t}=\mathrm{TT}_{t}+\mathrm{NTR}_{t}
$$

and the public deficit is given by:

$$
\mathrm{DEF}_{t}=\mathrm{GF}_{t}-\mathrm{REV}_{t}
$$

We suppose that the money supply adjusts itself to money demand, while real interest rates are used to target a desired inflation rate $\left(\pi_{t}\right)$.

$$
\begin{aligned}
\Delta \mathrm{DRR}_{t}= & 150\left(\Delta \log \mathrm{EE}_{t}-\pi_{t}\right)+50\left(\Delta^{2} \log E_{t}\right) \\
& +200\left(\Delta \log \mathrm{PPI}_{t}-\pi_{t}\right)+50\left(\Delta^{2} \log \mathrm{PPI}_{t}\right)
\end{aligned}
$$




$$
\begin{aligned}
\Delta \log \left(M 2_{t}\right)= & 0.4 \log \left(M 2_{t-1}\right)+0.2 \Delta \log \left(\mathrm{CPI}_{t-1}\right)-0.49\left(\log \left(M 2_{t-1}\right)\right. \\
& \left.-\log \left(\mathrm{CPI}_{t-1}\right)-\log \left(Y_{t-1}\right)+0.01 \mathrm{DR}_{t-1}\right)-\varepsilon_{t}^{M 2}
\end{aligned}
$$

\section{References}

Anderson, J., Barnard, G., Lauren, T., Roaf, J., Robinson, D., Rutkowska, I., Spatafora, N., McDonald, C, \& Santos, A. (2000). The Russian Federation: Selected issues. IMF Staff country report 00/150. Basdevant, O. (2000). An econometric model for the Russian Federation. Economic Modelling, 17, 305-336.

Bayoumi T., Coe, D., \& Helpman, E. (1996). R\&D spillovers and global growth. NBER Working Paper 5628.

Clements, M. R, \& Hendry, D. F. (1996a). Forecasting in macro-economics. In D. R. Cox, D. V. Hinkley, \& O. E. Barndorff-Nielsen (Eds.), Time series models: In econometrics, finance and other fields. London: Chapman and Hall.

Clements, M. R, \& Hendry, D. F. (1996). Intercept corrections and structural change. Journal of Applied Econometrics, 11, 475-494.

Clements, M. R, \& Hendry, D. F. (1998a). On winning forecasting competitions in economics. Institute of Economics and Statistics, University of Oxford, mimeo.

Coe, D., Helpman, E., \& Hoffmaister, A. (1995). North-South R\&D spillovers. NBER Working Paper 5048.

Feige, E. L., \& Pearce, D. (1976). Economically rational expectations: Are innovations in the rate of inflation independent of innovations in measures of monetary and fiscal policy? Journal of Political Economy, 84, 499-522.

Gavrilenkov, E., Henry, B., \& Nixon, J. (1999). A quarterly model of the Russian economy: Estimating the effects of a devaluation. London Business School, Centre for Economic Forecasting, DP 08-99.

Grafe, C, Kirsanova, T., \& Wyplosz, C. (1996). Pocket model oftheRussian economy. RECEP, mimeo.

Greenslade, J. V., \& Hall, S. G. (1996). Modelling economies subject to structural change: The case of Germany. Economic Modelling, 13, 545-559.

Hall, S. G. (1993a). Modelling structural change using the Kalman filter. Economics of Planning, 26, $1-13$.

Hall, S. G. (1993b). Modelling the sterling effective exchange rate using expectations and learning (Discussion Paper No. 33, 1990). Bank of England, The Manchester School.

Hall S. G., \& Basdevant, O. (1999). Measuring the capital stock in Russia: An unobserved component model. Mimeo.

Hall, S. G., \& Garratt, A. (1995). Model consistent learning: The Sterling deutschmark rate in the London Business School model. Economic Modelling, 12, 87-96.

Hall, S. G., \& Garratt, A. (1997). The stability of expectational equilibria in the LBS model. In C. Allen \& S.G. Hall (Eds.), Macro-economic modelling in a changing world. New York: Wiley.

Hall, S. G., \& Henry, S. G. B. (1988). Macro-economic modelling. Contributions to economic analysis series. Amsterdam: North Holland.

Hendry, D. F., \& Clements, M. P. (1998b). Economic forecasting in the face of structural breaks. In S. Holly \& M. Weale (Eds.), Econometric modelling: Techniques and applications. Cambridge: Cambridge University Press (Forthcoming).

Ivanova, N., \& Wyplosz, C. (1999). Arrears: The tide that is drowning Russia. Russian Economic Trends, 8(1), 24-35.

Kaminsky, G., \& Reinhart, C. (1999). The twin crises: The causes of banking and balance of payments problems. The American Economic Review, 89(3), 473-500.

Krugman, P. (1979). A model of balance of payments crises. Journal of Money Credit and Banking, 77(3), 311-325. 
Mishkin, F. (1996). Understanding financial crises: A developing country perspective. In M. Bruno \& B. Pleskovic (Eds.), Annual World Bank conference on development economics (pp. 29-62). Washington, DC: World Bank.

Stoker, J. (1994). Intermediation and the business cycle under a specie standard: The role of the gold standard in English financial crises 1790-1850. Chicago: University of Chicago, mimeo.

Temple, J. (1999). The new growth evidence. Journal of Economic Literature, 37, 112-156. 